\title{
Improving the Discoverability of Scholarly Content: Academic Library Priorities and Perspectives
}

\section{A SAGE White Paper}

Lettie Y. Conrad, MA,

Executive Manager, Product Analysis, Online Products Team

and

Elisabeth Leonard, MSLS, MBA

Executive Market Research Manager, Online Products Team 


\section{Contents}

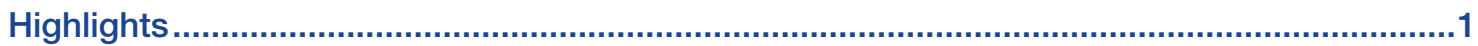

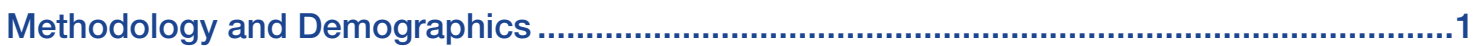

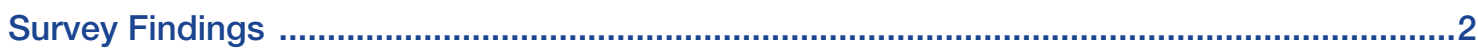

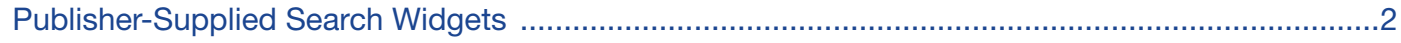

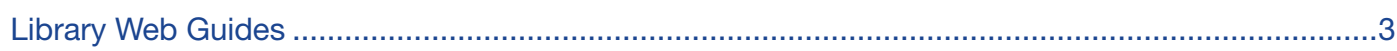

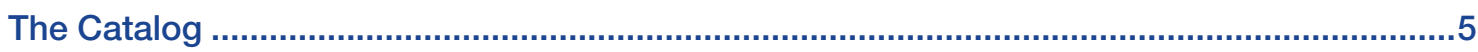

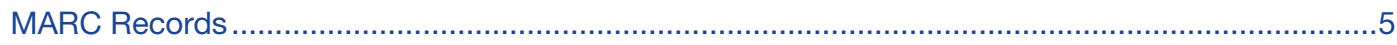

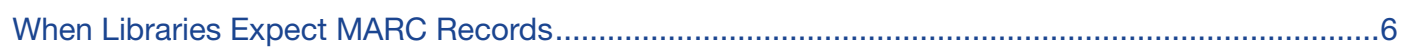

Quality of Publisher-Supplied MARC Records ………...........................................................

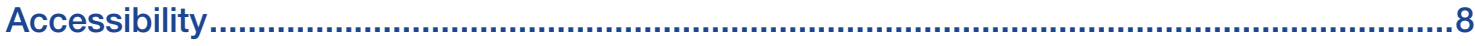

Web-Scale Library Discovery Systems .......................................................................

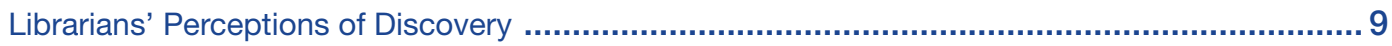

What Librarians Think Publishers Can Do to Optimize Discovery .........................................11

Impact of Publisher Choices on Library Purchases ............................................................12

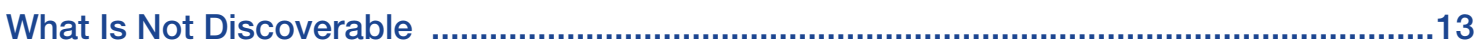

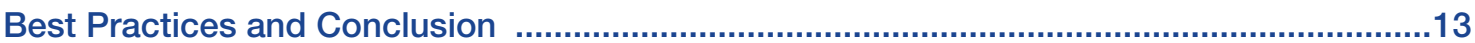

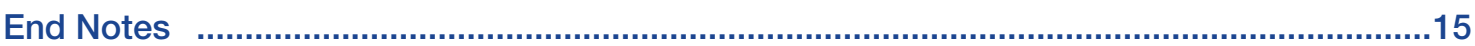


This paper draws on data gathered from a survey conducted by SAGE in February 2014, which garnered responses from 252 librarians about resource discovery practices and priorities. This data outlines key discoverability challenges and collaborative opportunities available to librarians and publishers. In keeping with the series of SAGE white papers on discoverability, ${ }^{1}$ this paper summarizes these survey findings and illuminates recommendations for industry best practices.

\section{Highlights}

The goal of this research was to capture today's most relevant discoverability issues to libraries. We sought to better understand library priorities and perspectives on how publishers can help enable discovery and access of licensed resources. The following highlights are explained in further detail in this report:

- The highest potential for increasing discovery was seen to be indexing in search engines, such as Google or Google Scholar, as well as indexing in academic aggregator databases, such as Scopus or EBSCO's Academic Search. Librarians encourage publishers to "get their metadata out there everywhere," because there is so much at stake if a resource goes unused.

- The library catalog remains a priority discovery channel for librarians. Therefore, publisher-supplied MARC records are needed most for print books, e-books, and videos. However, many survey respondents noted concerns with the quality and delays associated with these records, and expressed demand for higher-quality data at the point of sale.

- In terms of compliance with accessibility standards, $23 \%$ of librarians stated that it was required as part of the content license, $25 \%$ stated that compliance with accessibility standards was not required as part of the content license, and $44 \%$ of librarians did not know. Comments on accessibility compliance ranged widely from libraries that were not subject to accessibility legislation to those that believe that accessibility is the only thing that matters and so require it as part of their contract.

- When asked what expectations librarians have for publishers in optimizing discovery of licensed resources, librarians ranked the wide availability of metadata as the most important, followed by collaboration with library systems, standards compliance, and clear statement of content index coverage (transparency). The issue is serious enough that a lack of standards have prevented approximately $23 \%$ of librarians from purchasing/subscribing to scholarly resources, a lack of transparency has prevented about $33 \%$ of librarians from purchasing/subscribing to scholarly resources, a lack of collaboration has prevented about $26 \%$ of librarians from purchasing/subscribing to scholarly resources, and a lack of metadata has prevented almost $33 \%$ of librarians from purchasing/subscribing to scholarly resources.

- The least discoverable items are audiovisual materials, including streaming video, e-books, archival material (including digitized primary-source collections), dissertations, small publisher content, openaccess content, and business and legal content.

\section{Methodology and Demographics}

This report summarizes the results of a survey conducted in February 2014. The request to participate was sent to five mailing lists (LIBLICENSE, Colldev, LibResources, AcqNet, and AUTOCAT), calling for participation from academic librarians globally. Librarians who completed the survey could enter to win a drawing for one of ten $\$ 20$ Amazon gift cards.

The respondents represent an international sampling, with approximately $79 \%$ from North America, about 13\% from Europe and Central Asia, about 5\% from East Asia and the Pacific, 3\% from the Middle East and North Africa, and 1\% combined from South America and South Asia (see Table 1). 
Table 1 Geographic breakdown by region

\begin{tabular}{|l|c|c|}
\hline Total Response Count & \multicolumn{2}{|c|}{$\mathbf{1 6 8}$} \\
\hline Answer & Count & Percent \\
\hline East Asia and Pacific & 8 & $4.62 \%$ \\
\hline Middle East and North Africa & 5 & $2.89 \%$ \\
\hline Europe and Central Asia & 22 & $12.72 \%$ \\
\hline North America & 136 & $78.61 \%$ \\
\hline South America & 1 & $0.58 \%$ \\
\hline South Asia & 1 & $0.58 \%$ \\
\hline
\end{tabular}

The 168 librarians who responded to a question about their role in the library indicated that their primary role was indicated as being in electronic resources (more than 19\%), reference/research services (approximately 13\%), and collection development and management (approximately 12\%; see Table 2).

Table 2 Respondents' roles within their library

\begin{tabular}{|l|c|c|}
\hline \multicolumn{3}{|c|}{ Which of the following best describes your role in the library? } \\
\hline Answer & Count & Percent \\
\hline Access services & 9 & $2.82 \%$ \\
\hline Acquisitions & 15 & $4.70 \%$ \\
\hline Administration & 26 & $8.15 \%$ \\
\hline Cataloging & 23 & $7.21 \%$ \\
\hline Collection development and management & 36 & $11.29 \%$ \\
\hline Electronic resources & 62 & $19.44 \%$ \\
\hline Interlibrary loan & 1 & $0.31 \%$ \\
\hline Outreach and instruction & 24 & $7.52 \%$ \\
\hline Public services & 8 & $2.51 \%$ \\
\hline Reference/research services & 41 & $12.85 \%$ \\
\hline Scholarly communications & 12 & $3.76 \%$ \\
\hline Serials & 13 & $4.08 \%$ \\
\hline Special collections & 5 & $1.57 \%$ \\
\hline Technical services & 30 & $9.40 \%$ \\
\hline Web services & 14 & $4.39 \%$ \\
\hline
\end{tabular}

\section{Survey Findings}

The first section of the survey posed questions about the use of search widgets and library web guides to increase visibility and access to resources. These discovery tools are supplemental to what may be seen as the primary means of accessing published content: library catalogs, A-Z pages, discovery services, and open web-search engines (such as Google or Google Scholar). Many publishers provide widgets to search their content that can be embedded into web pages or into course management systems. Additionally, many libraries create web guides or virtual pathfinders for their content.

\section{Publisher-Supplied Search Widgets}

Use of publisher supplied search widgets is low, with only about $21 \%$ of librarians reporting that they use search widgets (see Figure 1). Many comments revealed that librarians are not sure what a search widget is. Also, use is low because librarians do not want to give any individual publisher preferential treatment (they feel that they need to provide a search widget for every publisher, so some librarians think of access via a widget as an all-or-nothing approach). 
Figure 1 Respondents' use of publisher-supplied search widgets

\section{Do you use publisher-supplied search widgets on your library website?}

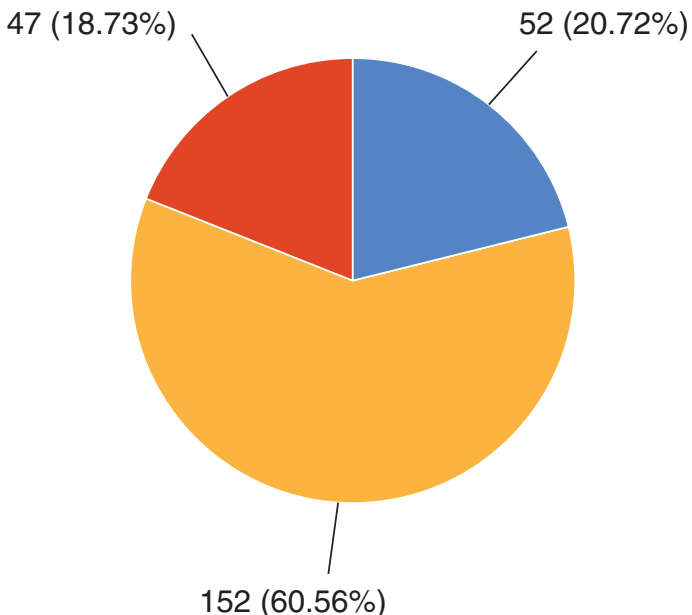

Yes No Don't know

\section{Library Web Guides}

The library web guides simulate the old-fashioned pathfinder and include subject guides, course guides, topic guides, and general guides for the research process. Due to the popularity of SpringShare's commercially available product LibGuides, the question refers specifically to LibGuides. About $82 \%$ of respondents reported that they regularly create research guides for their patrons (Figure 2).

Figure 2 Respondents' creation of research guides

Does your library regularly create research guides, like LibGuides, for your patrons?

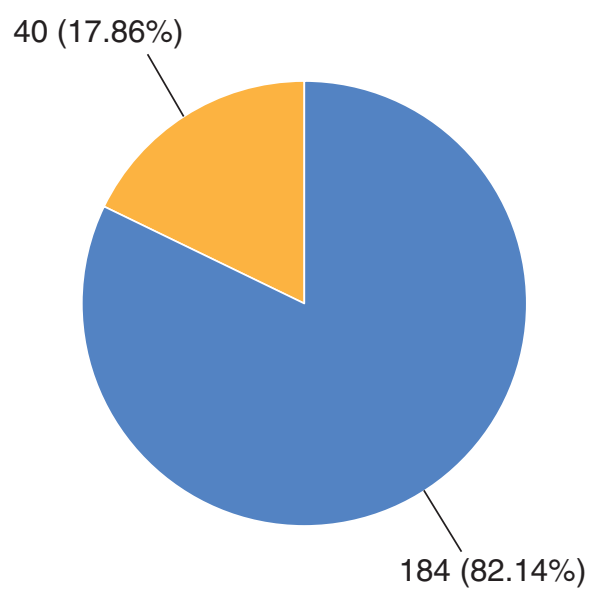

$$
\longrightarrow \text { Yes No }
$$


In order to support library efforts and to increase awareness and use of their products, some publishers have created their own research guides for use by librarians. Although we did not ask how aware librarians are of publisher guides, $45 \%$ indicated they would be likely to use a publisher-created guide, and $12 \%$ were very likely (Table 3 ).

Table 3 Respondents' likely use of LibGuides

If a publisher created a subject specific LibGuide with information about their resources on that subject, how likely would you be to use information from that LibGuide?

\begin{tabular}{|l|c|c|}
\hline & Number of responses & Percentage \\
\hline Very likely & 26 & 12 \\
\hline Likely & 101 & 45 \\
\hline Unlikely & 48 & 21 \\
\hline Very unlikely & 8 & 4 \\
\hline No opinion & 41 & 18 \\
\hline
\end{tabular}

Librarians are most interested in using some of the information from a publisher's guide within their LibGuide, rather than using a single publisher's guide in its entirety. This is because librarians want to provide access to all their resources, not to a single publisher, and because they want to eliminate any sales pitch from what their users see. They would use a LibGuide for tips on using a product. Librarians also would use a publisher's guide to assist in their collection development efforts.

Representative comments from participants include the following:

- "I might use the publisher-created guide myself as research in creating my own LibGuides-if that's what the question means, then I think they could be very useful. Librarians could use LibGuides from several different publishers to prepare one with a variety of resources from multiple publishers."

- "A lot of guides and other information created by vendors [are] more marketing than user support. I have used such content before, but usually have to edit it heavily for my own purposes, stripping out descriptions bloated by unnecessary adjectives and empty clichés."

- "For more-complicated products, detailed and well-organized help sites are helpful, whether as a LibGuide or within the publisher platform."

- "I would certainly look at a subject specific library guide created by a publisher, but would be more interested in integrating the information into our own guides. I would be hesitant to limit a student to one resource, no matter how thorough."

- "It is an ongoing challenge to update LibGuides. Such a service might make it easier."

- "I would like to see targeted, subject-specific search tips and information. What can I do and find in this resource that I can't do somewhere else? Also, if there are quirks in your system (searches that don't work the way one would anticipate, for example), explain why. Most publisher information focuses on a sales pitch and where to click, neither of which is all that helpful."

- "I find libguides from publishers to be tremendously helpful in learning to navigate new resources."

- "Whether or not I would use a publisher-provided LibGuide would depend on the quality of the information, the amount of publisherspeak on the guide, and the way information is presented. I would be unlikely to send students directly to any such guide, but I may adapt contents and/or link out to the guide if I find it to be high quality."

- "Library created research guides are not publisher specific and present a more balanced list of resources. No one publisher is the best for any subject area." 
- “We link to guides created by publishers from our LibGuides and resource records but don't usually re-use content from them."

- "If the libguide was responsive to each respective institution it would be very helpful. Example: a user clicks on the Sage Psychology Libguide, which lists ONLY the Sage resource my particular institution has purchased/has access to, not just a list of all the products available from Sage. No user wants to click on links that hit a paywall or denial of access message."

- "It would depend if those produced by publishers could be edited to add library logo etc."

- "Specific product training materials, e.g. brief video tutorials, are the vendor-created learning materials we are most likely to use."

\section{The Catalog}

The primary method for accessing library resources has traditionally been the library catalog. However, we wanted to learn what role the catalog plays for both print and electronic resources, what quality issues libraries face with MARC records, and what their expectations are for publisher-supplied MARC records.

\section{MARC Records}

Libraries use MARC records most for print books (nearly 95\%), followed by e-books (approximately $87 \%$ ), print journals (about 80\%), and e-journals (almost 68\%). Libraries use MARC records least for databases (about 40\%), data sets (slightly less than 12\%), or streaming video (slightly more than $41 \%$; Table 4).

\section{Table 4 Respondents' use of MARC records}

For which of the following does your library use MARC records? Please select all that apply.

\begin{tabular}{|l|c|c|}
\hline Answer & Number of responses & Percentage \\
\hline Print books & 198 & 94.74 \\
\hline E-books & 182 & 87.08 \\
\hline Print journals & 168 & 80.38 \\
\hline E-journals & 142 & 67.94 \\
\hline Data sets & 25 & 11.96 \\
\hline Databases & 84 & 40.19 \\
\hline Streaming video & 86 & 41.15 \\
\hline
\end{tabular}

Of these resources, librarians expect publishers to supply MARC records most for e-books (almost 42\%), print books (approximately 30\%), and streaming video (about 16\%; Figure 3).

There is an apparent decreased use of publisher-supplied records, potentially because libraries have implemented other resource management or discovery solutions. As noted by one participant, "Now that we have OCLC's WMS, MARC records provided directly by publishers are not as important." Some librarians reported that their use of these records varied depending on the quality of the records. Others are interested in publisher-supplied records for large, potentially changing collections; one participant stated, "I expect eBook vendors to provide records, just based on the vast nature of most subscription packages. It would be far too difficult and time-consuming to download individual records or catalog these kinds of items ourselves. We have fewer eJournals and print journals, so cataloging in house isn't as much of a burden." 
Of the resources below, for which do you expect a publisher to provide MARC records to your library?

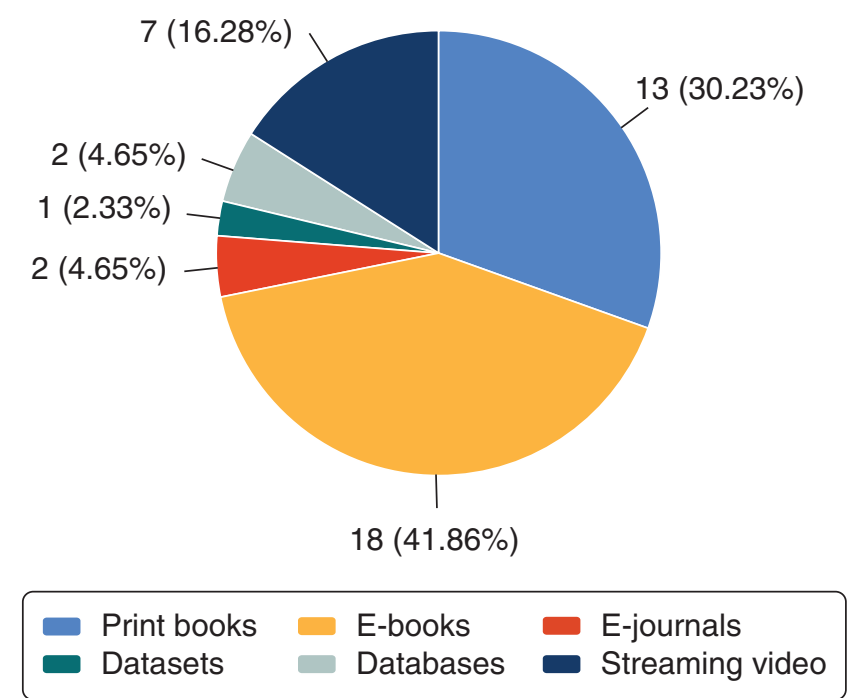

The following are additional comments from respondents:

- "We use MARC records for any content which we can access and for which we can get (free) MARC records! But now that we have EDS, the really important ones are for print books and ebooks. For content that is available via the EDS index, MARC records are not so important."

- "With EBooks, I absolutely will not look at a package unless it includes MARC records. For me to be able to make those books available for students, there has to be equal access for each person on campus so that I can make a catalog record without politics, and catalog records must be available with maintenance so that the publisher deals with linkrot. I cannot put links in catalog records and then monitor for linkrot, so that maintenance for the link is what I am looking for."

- "We want a unified search experience for our users, the more we can incorporate differing formats into the standard user experience the more likely our users are to discover them."

- "MARC records are key to the discoverability of our books and ebooks. Most of the use of our ebooks comes as a result of users seeing the MARC records that show up in their search results in our catalog and in our discovery layer (Summon) and clicking on those records to link to the books. We know this because searches in our ebook products are low (and falling), but sessions and full text downloads are rising."

- "The quality of ebook records varies considerably. Also there are great differences in timing of when publisher metadata is distributed to knowledge base providers (e.g., link resolver, ERM, OCLC). It would be extremely beneficial to end users (as well as to libraries) if the distributed metadata were more robust and distributed in a more timely manner."

- "We use OCLC, RLUK collaborative cataloguing tools for print format MARC records. For e-resources we currently take data from our link resolver targets."

\section{When Libraries Expect MARC Records}

Almost $67 \%$ of librarians expected MARC records to be provided at the point of sale or on request, and approximately $63 \%$ expected to receive MARC records on request (see Table 5). Respondents were able to select one or more choices, so the number of responses varies by statement. 
Table 5 Respondents' expectation of receiving publisher-created MARC records

Question: When do you expect a publisher to make MARC records available? (Please select all that apply.)

\begin{tabular}{|l|c|c|}
\hline Answer & Number of responses & Percentage \\
\hline At the point of sale/signed license agreement & 125 & 66.84 \\
\hline Upon publication of new content & 118 & 63.10 \\
\hline As requested & 84 & 67.20 \\
\hline We don't use publisher-supplied MARC records & 23 & 18.40 \\
\hline Don't know & 11 & 13.10 \\
\hline
\end{tabular}

When libraries use a publisher's MARC records, they mostly use batch-loaded records (slightly more than $62 \%$ ) over individual MARC records (approximately 41\%; Table 6). Batch loading is seen as a way to save staff time.

\section{Table 6 Respondents' use of MARC records}

Question: Which of the following publisher-supplied MARC records does your library use? Please select all that apply

\begin{tabular}{|l|c|c|}
\hline & $\begin{array}{c}\text { Number of } \\
\text { responses }\end{array}$ & Percentage \\
\hline Batch-loaded MARC records & 115 & 62.16 \\
\hline Individual item MARC records & 76 & 41.08 \\
\hline Prepublication MARC records & 11 & 5.95 \\
\hline Postpublication MARC records & 30 & 16.22 \\
\hline None of the above & 24 & 12.97 \\
\hline Don't know & 41 & 22.16 \\
\hline
\end{tabular}

\section{Quality of Publisher-Supplied MARC Records}

Comments regarding the quality of publisher-supplied records generally illustrate that librarians think the quality is low, although some librarians are satisfied with the quality (which seems dependent on which publishers they use as well as original expectation of level of quality):

- "Quality can be pretty dreadful-often the metadata for the records is machine harvested and doesn't actually make sense in the record. For example, there may be a hundred added author entries for one ebook, with all of the authors taken from individual articles, and some authors listed multiple times under multiple versions of their name. A great deal of cleanup is needed to use these records."

- "Many publisher supplied MARC records especially for journals are of poor quality."

- "Quality is a big issue. Biggest problems we have seen are lack of name authority control (so authors are listed many ways), lack of good subject headings, lack of series information, problems with ISBNs which prohibit matching with integrated systems such as SFX, discovery system."

- "While we don't necessarily expect completeness from vendor/publisher supplied records, we do expect accuracy, and this expectation is not met consistently."

- "Most MARC records from publishers have been of pretty decent quality. They have greatly increased the use of some our resources since they're searchable in the OPAC." 


\section{Accessibility}

Many respondents (about 42\%) had no expectation regarding how publishers should address accessibility issues. For some respondents, this was someone else's area of expertise, but for others, it does not seem to be a consideration in their libraries. For librarians who were concerned about accessibility standards and publishers, W3C Web Accessibility Initiative received the most note (almost $28 \%$ ), followed by regional policies such as Section 508 (nearly 17\%) and the TAC checklist (slightly more than 5\%; see Figure 4).

\section{Figure 4 Respondents' expectations of publisher-applied accessibility standards}

Which of the following accessibility standards do you expect a publisher to have applied to online products?

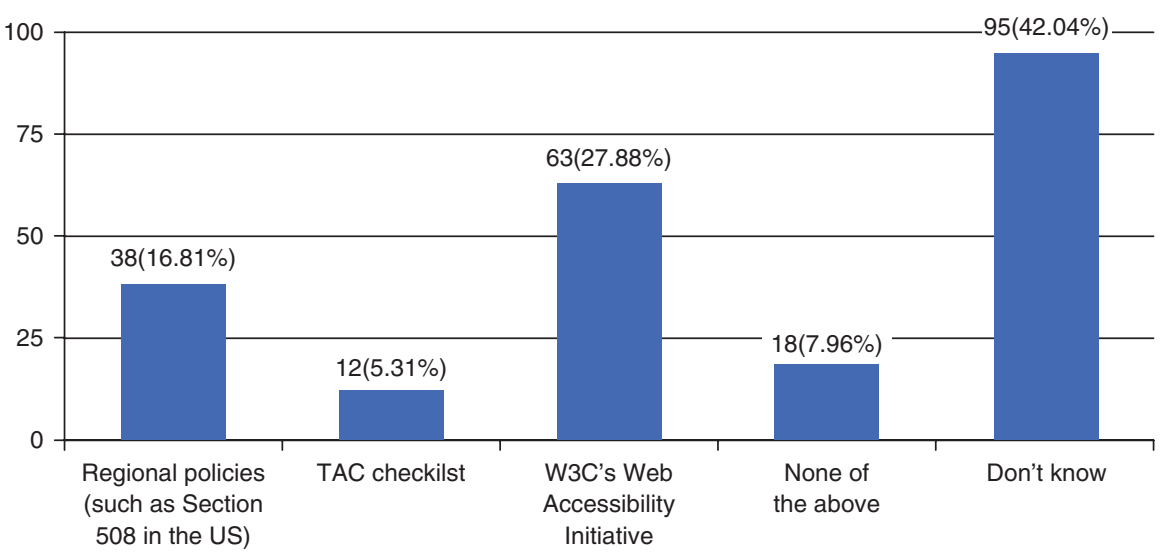

In terms of compliance with accessibility standards, approximately $23 \%$ of librarians stated it was required as part of the content license, about $25 \%$ stated compliance with accessibility standards was not required as part of the content license, and slightly more than $44 \%$ of librarians did not know (see Figure 5).

Comments about accessibility compliance ranged widely from libraries that were not subject to accessibility legislation to those that believe accessibility is the only thing that matters and so require it as part of their contract. Following are some comments we received:

- "We will no longer purchase content that doesn't include a compliance statement on the license. We review content using JAWS and other accessibility software during trial periods. We give useful feedback to vendors on the usually minor changes that make a big difference. We have already rejected purchases based on non-compliance. We have an excellent disability services office, and a large population of students requiring various assistive devices, and will no longer condone publishers who refuse to make their content compliant."

- "Our university is in the process of requiring complete accessibility. So soon we may be required to cancel subscriptions to large well used collections."

- "It's not required, but it's definitely something that factors into collection development decisions. Libraries are about access for everybody."

- "So far, the impact has been small, but we are more likely to buy content that natively is 508 compliant. PDFs should include text or OCR, videos and audio should have transcripts, datasets should have human-understandable metadata, etc." 
Figure 5 Respondents' compliance requirements regarding accessibility standards

Do you require compliance with accessibility standards as part of your content license?

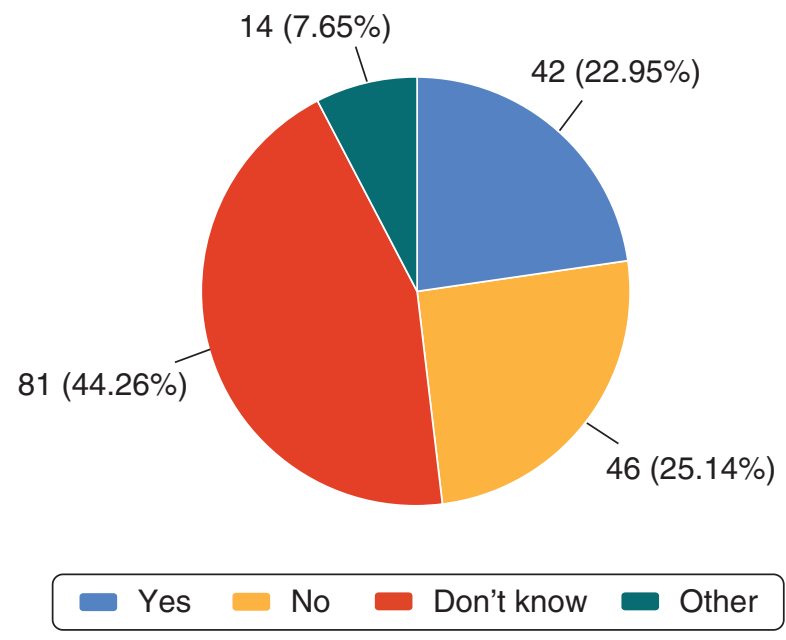

- "It is becoming increasingly important on our campus, we are more aware of the needs on campus and are working with vendors to provide accessible content whenever possible. Most important for e-resources and DVDs to be compliant with screen readers, include captions, etc. We have rejected select DVDs/streaming content because they were not compliant but this is a new practice for us."

- "Lack of accessibility does not currently prevent purchase but may in the future. We routinely test publisher interfaces for accessibility and report results to publishers."

\section{Web-Scale Library Discovery Systems}

In addition to the catalog and library A-Z lists, web-scale discovery services have become a major entry point to a library's resources. About $65 \%$ of librarians reported they have a web-scale resource discovery service, such as EDS, WorldCat Discovery, Primo, or Summon (see Table 7).

\section{Table 7 Respondents' use of web-scale resource discovery services}

Question: Does your library offer a pre-indexed web-scale resource discovery service (such as EDS, Summon, or Primo)?

\begin{tabular}{|l|c|c|}
\hline \multicolumn{2}{|c|}{ Total Response Count } & \\
\hline Answer & Number of responses & Percentage \\
\hline Yes & 119 & 65.03 \\
\hline No & 57 & 31.15 \\
\hline Don't know & 7 & 3.83 \\
\hline
\end{tabular}

For those who do not have a discovery service now, 30 librarians (45\%) were planning to implement a discovery service soon.

\section{Librarians' Perceptions of Discovery}

To the question of what has the greatest impact on discovery of licensed content for their libraries, librarians believe that information literacy, indexing in Google, and indexing and web-scale discovery services have the greatest impact (see Table 8). 
Table 8 Respondents' perceptions of greatest impact on discovery

Question: Which of the following currently has the greatest impact on the discovery of licensed resources at your library? (check all that apply)

\begin{tabular}{|l|c|c|}
\hline Total Response Count & Number of responses & Percentage \\
\hline Answer & 107 & 59.44 \\
\hline $\begin{array}{l}\text { Information literacy/research instruction } \\
\text { stream search tools }\end{array}$ & 99 & 55.00 \\
\hline $\begin{array}{l}\text { Content indexed in library "web-scale" } \\
\text { discovery services }\end{array}$ & 104 & 57.78 \\
\hline MARC records available from the publisher & 54 & 30.00 \\
\hline LibGuides or other research guides & 64 & 35.56 \\
\hline Search widgets & 10 & 5.56 \\
\hline Other & 12 & 6.67 \\
\hline
\end{tabular}

The highest potential for increasing discovery was seen to be indexing in search engines, such as Google and Google Scholar, and indexing in academic aggregator databases, such as Scopus and EBSCO's Academic Search (see Table 9).

Table 9 How librarians expect publishers to optimize the discovery of licensed resources

Question: Which of the following has the highest potential to improve discovery of licensed resources at your library?

\begin{tabular}{|l|c|c|}
\hline Total Response Count & Number of responses & Percentage \\
\hline Answer & 53 & 31 \\
\hline Indexing in open-web search tools (like Google, Bing) & 53 & 30 \\
\hline $\begin{array}{l}\text { Indexing in open-web academic tools (like MS Academic } \\
\text { Search, Google Scholar) }\end{array}$ & 14 & 8 \\
\hline Indexing in subject databases (like PubMed, ABI Inform) & 40 & 23 \\
\hline $\begin{array}{l}\text { Indexing in aggregator databases (like Academic Search, Lexis } \\
\text { Nexis) }\end{array}$ & 14 & 8 \\
\hline Other & & \\
\hline
\end{tabular}

Comments about the relative priority of efforts to increase discoverability demonstrated the importance of publishers investing in both mainstream and library search tools, such as:

- "I would say either Google or Google Scholar. Because Google Scholar provides 'Find in My Library' linking, we instruct users to use Google Scholar (as it frequently happens where content is available from a third-party provider such as EBSCO or ProQuest)."

- "Although implementation of WorldCat Local has significantly improved use of online library resources, it is inevitable that many students end up using Google at some point. Thus, having as many of our resources accessible there as possible can only further improve use of academic resources (albeit with the need for additional information literacy training). It's surprising how much of the traffic to our Springer subscriptions comes from Twitter and you can tell this by the referring URL being a t.co url. So google in the near future, but Twitter is important, too." 
- "I wish that our students made subscription databases their first stop for conducting research. User studies we recently conducted clearly told us that they make Google their first stop. As a librarian I feel that it is very difficult to conduct thorough, rigorous academic research using only Google or Google Scholar. If our first years are mostly using those products they are probably satisficing a lot. In any case, I have to say that open web is probably where our students are currently doing most discovery. We have to teach students to use library resources and hopefully they get the message, but it's not clear to what degree our library instruction is actually changing how students conduct research when they are in a time crunch and stakes are high."

- "I think vendors should be as indiscriminate in getting as much metadata about their resources as possible. Exclusive deals are insanely dumb-if a publisher only includes their metadata in primo, and I'm not a primo customer - we'll never purchase that content and our users will never find it. Why waste money on publishers' offerings if they can't be used? Get that metadata out there everywhere."

\section{What Librarians Think Publishers Can Do to Optimize Discovery}

When asked what expectations librarians have for publishers in optimizing discovery of licensed resources, librarians ranked the wide availability of metadata as the most important, followed by collaboration with library systems, compliance with standards, and clear statement of content index coverage (see Table 10).

Table 10 How librarians expect publishers to optimize the discovery of licensed resources

\begin{tabular}{|l|c|}
\hline Choice & Rank \\
\hline $\begin{array}{l}\text { Metadata: Wide availability of content metadata in both mainstream research } \\
\text { tools and library systems }\end{array}$ & 1 \\
\hline Collaboration: Efforts to optimize content discovery within library systems & 2 \\
\hline Standards: Compliance with all ratified standards for scholarly content discovery & 3 \\
\hline Transparency: Clear statement of content index coverage & 4 \\
\hline
\end{tabular}

The following are comments we received regarding librarians' expectations:

- "Standards are the most important. This should also INCLUDE a 'clear statement of content index coverage' in any record that has an extent limitation."

- “They're ALL important. I can't really rank them as I can come up with scenarios where problems in each of these areas strongly affects discovery."

- "All of the above are critical in improving discovery of licensed resources, particularly in relation to the discovery services (eg: WorldCat Local). I would add that it would be helpful for publishers to urge database providers (EBSCO, ProQuest, etc.) to also work more closely and openly with discovery services."

- "Transparency and compliance with standards should be bare minimum requirements; they cannot be considered something special that might be ignored or given minimal importance. I would not even consider a publisher that did not fully support transparency and standards compliance. It shouldn't even be necessary to ask."

- "The importance of good quality metadata for inclusion in web scale discovery systems cannot be emphasized enough!"

- "We have been very disappointed in the uptake of content providers to allow content indexing in discovery tools." 
- "Be open and clear about what your resources cover, how your search algorithms will function, and what the limitations of your resources and services are. We already know that you don't have and can't do everything - and we don't expect you to. But, I don't want to have to discover these things for myself because the publishers and vendors aren't upfront. Since it's in both of our best interests to ensure that these resources are being well used, I expect you to work as hard as I and my colleagues do to meet this objective."

- "Better quality metadata is needed. Name recognition for publishers has dwindled and people are more focused on the individual data they require rather than a vast number of results."

- "Standards + metadata go hand and hand. Available metadata that has fuzzy, imprecise ability to link to a library's purchased content (due to not following standards that article linkers can follow) is not as much use to us."

- "All of the above are important. Right now we are seeing a major disruption to the information access paradigm and vendors/websites/commercial sector seem in more control of potential outcomes (libraries have no R\&D); HathiTrust and others are out there but don't have the support to make a difference."

- "Very disappointed that vendors do not use their discovery tools with competitors' content."

- "For me, accuracy of metadata is an important prerequisite before vendors can worry about wide availability of metadata. Initiatives like IOTA and KBART have released important recommendations that more vendors need to adopt. The metadata supply chain is one of the biggest barriers to discovery currently facing publishers and libraries."

\section{Impact of Publisher Choices on Library Purchases}

Librarians were asked to respond to three statements relating to publisher participation (compliance with standards, provisions of clear statements about content index coverage, and making their metadata widely available). The respondents could select multiple responses from these three statements, so the response rate varies by each statement. A lack of standards prevented approximately $23 \%$ of librarians from purchasing/subscribing to scholarly resources for their libraries, a lack of transparency prevented about $33 \%$ from purchasing/subscribing to scholarly resources, a lack of collaboration prevented approximately $26 \%$ from purchasing/subscribing to scholarly resources, and a lack of metadata has prevented slightly fewer than $33 \%$ from purchasing/subscribing to scholarly resources (see Table 11).

Table 11 Situations preventing respondents from purchasing/subscribing to resources Question: Have any of the issues below impacted your library's decision to purchase or subscribe to a resource?

\begin{tabular}{|l|c|c|}
\hline \multicolumn{2}{|c|}{ 171 Responses } \\
\hline & Yes & No \\
\hline $\begin{array}{l}\text { Standards: Compliance with all ratified standards for } \\
\text { scholarly content discovery }\end{array}$ & $\begin{array}{c}37 \\
(22.56 \%)\end{array}$ & $(77.44 \%)$ \\
\hline Transparency: Clear statement of content index coverage & 55 & 109 \\
& $(33.54 \%)$ & $(66.46 \%)$ \\
\hline $\begin{array}{l}\text { Collaboration: Efforts to optimize content discovery } \\
\text { within library systems }\end{array}$ & 43 & 122 \\
\hline $\begin{array}{l}\text { Metadata: Wide availability of content metadata in both } \\
\text { mainstream research tools and library systems }\end{array}$ & $(26.06 \%)$ & $(73.94 \%)$ \\
\hline
\end{tabular}




\section{What Is Not Discoverable}

Survey respondents indicated that the least discoverable items in their libraries are audio-visual materials, including streaming video, e-books, archival material (including digitized primary-source collections), dissertations, small-publisher content, open-access content, and business and legal content. With scholarly works presented in dozens of formats, each with unique metadata standards at varying levels of maturity, discoverability challenges arise across the search and indexing landscapes. All search engines treat content metadata a little differently because each has a unique algorithm. For instance, an encyclopedia entry is shorter than a journal article, which means that the keyword ranking will be more condensed and could have an impact on relevancy ranking in search results. And some content, such as images or multimedia, may be published without sufficient metadata for indexing.

\section{Best Practices and Conclusion}

The realities of how students discover and use academic resources are of critical importance to librarians, publishers, technologists, and all stakeholders in higher education and scholarly communication. Studies such as the surveys summarized in this report-and other relevant publications ${ }^{2-}$ highlight many areas for collaborative improvements toward a more optimized environment for content discovery and usage.

Broadly, the distribution of this survey data represents the benefits of an open dialogue and coinvestment in our collective success. There are opportunities for both publishers and libraries to more closely assess the effectiveness of cross-sector initiatives and developments, such as devices that use application programming interfaces (APIs), search widgets, and metadata and indexing techniques, among others. This study points to the need for the academic community to come together to improve the visibility of unique and new types of content, such as multimedia material. And these results again reinforce the necessity of collective formation and governance of digital information standards, such as the Open Discovery Initiative, led by the National Information Standards Organization. ${ }^{3}$ Also, publishers and librarians can glean evolving best practices from these data to inform their own strategic decisions toward collaborative improvements to discoverability.

The findings of this survey can positively influence publishers' marketing and product development strategies. The data demonstrating librarians' expectations are important for publishers to internalize and, whenever possible, ensure sufficient investments are made to optimize product discoverability, publication metadata, and standards compliance. This includes continually investigating new opportunities for indexing, monitoring discoverability performance, and informing platform development roadmaps to ensure library systems interoperability and open web visibility. These investments are not trivial but are of core importance to online product success.

These findings suggest that publishers will enjoy positive market response and strong usage when they are able to more broadly participate in open web and library resource discovery and access tools. The collective value of high-quality, accurate, and standards-compliant metadata cannot be understated and has an impact on a wide variety of discovery channels. For example, a majority of librarians indicated their interest in accurate and timely MARC records from publishers - metadata that can also feed webscale discovery systems, such as EDS. Publishers can therefore conclude that offering customers MARC records of the highest possible quality would benefit their sales and usage; in particular, publishers should focus their investments on data for books and video.

Librarians can take heart that publishers have a vested interest in adequate discovery and access of their content. Reinforcing library priorities via industry conferences and social media, sales meetings, research opportunities, and information standards initiatives is critical to our collective efforts toward improved resource discovery.

There are other tactical conclusions that can be drawn from this study. The notable interest in LibGuides presents an outstanding opportunity for strategies to deliver generic subject- or course-based guidesthey allow LibGuide customers a "starter" guide that they can customize for their institution. These 
guides also contribute to open web search engine optimization (SEO). Conformance with accessibility and metadata standards are having an impact on content licensing decisions, and publishers should begin to consider discoverability improvements as critical investments.

In sum, this survey demonstrates strong publisher interest to learn from the librarian experience and motivation to address institutional needs for discoverability and accessibility. Conversely, libraries have an opportunity to engage directly with publishers as partners, contribute to surveys such as the one presented in this report, and be open to co-development opportunities. Together, we can evolve the scholarly discovery ecosystem, by uniting to establish and champion information standards and continuing the open dialogue. 


\section{Endnotes}

1. Mary M. Somerville, Barbara J. Schader, and John R. Sack, "Improving the Discoverability of Scholarly Content in the Twenty-First Century," white paper, SAGE Publications, Thousand Oaks, CA, 2012, http://www.sagepub. com/repository/binaries/librarian/DiscoverabilityWhitePaper; Lettie Conrad and Mary M. Somerville, "Collaborative Improvements in the Discoverability of Scholarly Content: Accomplishments, Aspirations, and Opportunities," white paper, SAGE Publications, Thousand Oaks, CA, 2014, http://www.sagepub.com/repository/binaries/pdf/ improvementsindiscoverability.pdf.

2. Suzanne Saskia Kemperman, Bill Brembeck, Elizabeth W. Brown, Alexandra de Lange-van Oosten, Theodore Fons, Catherine Giffi, Noah Levin, Alistair Morrison, Carlen Ruschoff, Gregg A. Silvis, and Jabin White, "Success Strategies for Electronic Content Discovery and Access: A Cross-Industry White Paper," Online Computer Library Center, Dublin, OH, 2014, http://www.oclc.org/content/dam/oclc/reports/data-quality/215233-SuccessStrategies .pdf.

3. National Information Standards Organization, "Open Discovery Initiative," http://www.niso.org/workrooms/odi/. 
